Kohl: a Journal for Body and Gender Research

Vol. 3, No. 1 (Summer 2017)

\title{
Against Assimilationist Projects: Towards Queering Our Political Imaginations
}

Lara Bitar 
Pride incorporated made its debut in Lebanon this year - without its historical precursors of sustained confrontation of hegemonic culture, militant resistance, or anti-police agitation - as a registered trademark. Despite the country's rich history of strategic and courageous organizing, the pride week that landed in Beirut in 2017 was unable to imagine, let alone create an opening for a localized queer futurity. ${ }^{1}$ It did, however, actualize the partial vision of a future that merely reproduces the present of a corporatized Western gay mainstream. If this vision is materialized, upper middle class cisgender gays will be inching toward greater freedoms at the expense of the "unrespectable" poor, gender non-conforming, and paperless trans and gay communities.

While the articulation of queer political imaginations and potentialities is an urgent project, it must necessarily be the product of a collective labor. ${ }^{2}$ My aim here is to simply highlight conceptions and associations that antagonize or threaten liberation premised on social and economic justice, situating myself as a proponent of the latter.

The adversaries of liberatory projects have spent years co-opting grassroots movements through their NGO-ization while selling the idea that the market provides solutions to all social ailments. ${ }^{3}$ At the same time, as the commons narrow and the fetishization of late capitalist individualism prevails, with startup culture as its latest manifestation, the local market was ripe for Beirut Pride ${ }^{\mathrm{TM}}$ (BP). Promoting itself as a "collaborative platform that takes a positive stance against hate and discrimination," BP is in reality the product of an individual effort that generated some events and aggregated others into a weeklong celebration of "humanity." 4 The initiative was a ravishing success with the targeted gay and to a lesser extent lesbian communities that were already somewhat visible, but starving for wider acceptance and a defiant display of their existence.

The mindset for BP was instilled in these communities by another import problematized by queer activists in the region many years ago, the International Day Against Homophobia and Transphobia (IDAHOT), first recognized in Lebanon as IDAHO in 2005.5 To the liberal mind, "homophobia" and "transphobia" exist in some sort of vacuum and thus can be fractured or weakened in isolation from the material and social

\footnotetext{
1 Queer futurity is an attempt to break with the present in exchange for "concrete utopianism," and includes a rejection of gay pragmatic organizing in favor of queer idealism. This understanding is drawn from queer theorist José Esteban Muñoz' ideas in Cruising Utopia: The Then and There of Queer Futurity.

2 In this piece, I use the term "queer" either for those who self-identify as such, or to seek distance and differentiation from "gay," both terms used as gender neutral unless otherwise implied. While queer could reference a nonnormative sexual or gender identity, it is its connection to radical politics (as in politics grasped at by the root), its rejection of the politics of recognition, and its practice of "queering" (as in deconstructing, subverting, and disrupting dominant discourses, structures, ways of seeing, etc., to ultimately create new worlds) that my use of the term underlines.

${ }^{3}$ Roy, Arundhati. "Public Power in the Age of Empire." The End Of Imagination, 1998.

${ }^{4}$ Beirut Pride Statement, 2017, available at: https://www.beirutpride.org/english-statement

5 One of these critiques, offered by Palestinian queer activists Haneen Maikey and Sami Shamali, argues that the anti-homophobia discourse is being used for other oppressive ends, available at: http://www.bekhsoos.com/2011/05/international-day-against-homophobia-between-the-western-experience-and-thereality-of-gay-communities/
} 
structures that uphold them. Similarly, the pride held in Beirut was stripped of a contextualized political discourse, advancing "positivity" and warm feelings in its stead - alongside a strong plea for visible incorporation into a specific segment of Lebanese society. The initiative, which centered economically privileged gay men and catered to their consumption habits, was intentionally depoliticized to ensure its materialization. ${ }^{6}$ While BP claims to build on the decades-old work of lesbian, gay, bisexual, and transgender (LGBT) activists, its refusal to take a symbolic stand on virtually any issue makes it a deviation from that work. ${ }^{7}$ It was so politically neutralized that it even diverged from the dominant human rights discourse advanced by most NGOs, opting for vague liberal notions of transcending labels, rather than engaging with structural violence, most harshly experienced by transwomen in Lebanon.

More insidiously, its disregard for local queer feminist histories and the knowledge and frameworks produced by the feminist network Sawt Al Niswa and previous members of the LBTQ group Meem could be read as an attempt to negate that very work BP highlights for legitimacy. By insisting on presenting itself to the media as apolitical to appease the religious and political establishment, this initiative reveals itself as a reactionary assimilationist project more vested in minor privileges for a few, namely unmolested prideful visibility, than in dismantling the heteropatriarchy that queer and radical feminists have been scheming for, under different formulations, for decades. ${ }^{8}$

Through its collaboration with Beirut Design Week (BDW), BP focused on representation, appearance, and fashion, hosting some events in Jisr el-Wati, an industrial zone turned elitist contemporary art hub, and others in trendy bars and clubs. The aim was seemingly to exhibit the connection between middle-class gays on one hand and "innovators," partygoers, and designers on the other, firmly placing gay men on the side of universal progress and its dehistoricized homophobe/gay-friendly binary. Many of these gay-friendly allies have set up their studios and galleries in the gentrifying neighborhood of Mar Mkhayel which, not coincidentally, was also the site of a spontaneous bar-hopping evening that concluded both IDAHOT and pride week.

Prominent organizations such as Helem and Marsa, who at one point or another distanced themselves from BP, saw their interests coalesce in Mar Mkhayel. The latter, a residential neighborhood engaged in a years-long battle with bar owners and the Municipality of Beirut, had just renewed a public campaign to demand "the right to sleep."9 Despite the neighborhood's transformation into a contested space, with real

${ }^{6}$ The manner in which NGO-organized talks and events became a part of the BP program is disputed (as informed by my interviews and informal conversations with various activists and organizers) and, for this reason, ignored for the purpose of this piece. In this critique, I refer to BP-produced events alone and/or in collaboration with Beirut Design Week, not the IDAHOT events organized by NGOs and allegedly appropriated by BP. The full program is available at: https://www.beirutpride.org/

7 Qiblawi, Tamara. "Beirut gay pride event a first for Lebanon." CNN, May 16, 2017, available at: http://edition.cnn.com/2017/05/16/middleeast/beirut-gay-pride/index.html

8 Kaedbey, Deema. "Shadow Feminism in Lebanon, Part Two." Sawt Al Niswa, January 2015, available at: http://www.sawtalniswa.org/article/481

${ }_{9}^{9}$ Mar Mikhael residents' open letter to the Municipal Council of Beirut and the Beirut Governor. May 12, 2017, available at: 
estate developers seeking to exclude and displace longstanding residents from their homes, it became a marker of inclusivity for gays and lesbians that night. A colorful and exuberant rainbow-filled celebration not without its merits - culminated a difficult week for LGBT organizations who had faced a series of threats by extremist groups.

Because of these threats, two IDAHOT events were canceled at the last minute, so the celebratory spirit of that night expressed both relief and joy at the public embrace by Mar Mkhayel establishments. At the same time, it displayed the potential contradictions of these communities' incorporation into a mainstream that mostly ignores the presence and well-being of others. It also underscores how intention-lacking organizing, or in this instance a spectacle of public consumption, can score victories at the expense of other movements. The hashtag "Stain of Shame" (English for wasmat aar), created by a coalition of NGOs to denounce the repression it faced, was appropriated by a few who dared to dissent from the nearunanimous approval of these tactics. Such voices expressed disgust with the pursuit of narrow and fleeting self-interest at the expense of the large struggle.

Moreover, a cursory view of the visual material generated during various events reveals the production of an acceptable and respectable gay aesthetic: young, well-groomed, able-bodied, and cisgender individuals with a disposable income. ${ }^{10}$ This ideal gay subject is worthy of visibility and hence inclusion as a model of diversity within capitalist culture. As a matter of fact, while a number of advertising agencies have flirted with implicit representations of gays and lesbians in their commercials, fast-food chain Crepaway made the leap this year by briefly depicting a young and attractive femme couple in an English-language advertisement. The web-only ad was enthusiastically received and widely shared by LGBT individuals because, as writer and troublemaker Mattilda Bernstein Sycamore aptly explains, "consumer gay culture [is] satisfied with glossy representations as a sign of progress." 11 Contributors to the now-defunct Bekhsoos, an online Arab magazine published by queer and trans folks, had spent years envisioning, constructing, and actualizing local and contextual manifestations of progress for LGBT communities - all of which were displaced for a shallow Western signage. ${ }^{12}$

Alongside the anticipated exploitation of LGBT imagery by capital, the manufacturing of these normative citizen-subjects also requires their absorption into a nationalist discourse that regards refugees and migrants as a threat to national security. The self-proclaimed "first pride in the Arab world" requested and received the protection of the Internal Security Forces (ISF) on the basis of the right to equal protection under the law as citizens of this country - without informing its participants, or publically announcing the

https://www.facebook.com/BeirutMadinati/photos/pcb.1361102513969499/1361101047302979/?type=3\&theater

10 Some of the visual material aggregated from Instagram, available at: https://unicornbooty.com/beirut-pride-lgbtlebanon/

11 Bernstein Sycamore, Mattilda. "City of Brotherly Love." The New Inquiry, 10 Feb. 2015, available at: www.thenewinquiry.com/city-of-brotherly-love/

12 Lynn. "Framing Visibility: Coming Out and the International LGBT Spectrum of Progress." Bekhsoos, 12 Dec. 2010, retrieved from: http://thebridgebrant.com/wp-content/uploads/2014/03/Queer-Women-Framing-Visibility-and-Coming$\underline{\text { Out.pdf }}$ 
police's presence. Understanding the detrimental impact of homoantagonism and transantagonism on the lives of LGBT people and being mindful of their safety when organizing an outing is commendable. ${ }^{13}$ However, it is a grave mistake to disregard what is arguably the harshest form of violence against bodies perceived as deviant: state violence and persecution. This seemingly well-intentioned attempt to ensure the safety of the attendees erases the well-documented violence of successive Lebanese governments against LGBT-identified people, stateless and undocumented individuals, and migrant workers. More troublingly, it reasserts the power of the state to arbitrate social questions and produce a reality that, in this instance, universalizes tolerance or acceptance of a certain representation of gayness and a demonization of others.

Talk to Shadi about his experience with this same ISF that BP appealed to for support and he'll describe in detail the torture he endured for being a gay Syrian refugee. ${ }^{14} \mathrm{~S}$., another Syrian refugee, will quote his tormentors: "Aren't you ashamed to be a faggot on a Friday, you dishonorable lout! You're Syrian and you're doing this in our country!" 15 S.' detention would later lead to the violent Hammam al-Agha raid and the mass arrest and humiliation of Lebanese and Syrian gay men by the Internal Security Forces (ISF). ${ }^{16} \mathrm{~A}$ 2013 Human Rights Watch (HRW) report documented how Lebanese "police do little to hide their disdain of drug users, sex workers, and LGBT people," explaining that "verbal abuse, degradation, and humiliation appear to be so common that many victims tended to gloss over them when telling their stories." 17

Countless testimonies of formerly detained individuals allow me to speculate that the ISF would never provide security at the cruising spots frequented by working-class and displaced gay men, but would gladly entrap then torture them. Revealing a longing to be rescued from individual acts of violence by a state apparatus that casually disposes of undesirables, this project creates then reinforces a binary between the good and proud gay-identified men, as represented by BP, and the men who sleep with other men, seen as sexually deviant and a threat to the social order because of their class or citizenship status. The normalization of the former inadvertently creates a duality that delegitimizes and further disenfranchises the new non-normative sexual and gendered "others," who refuse to, or cannot conform to the homonormativity imposed by this universal gay.

In the face of harsh containment policies adopted by the Lebanese state against migrant and otherized bodies, queers have a duty to disrupt single-issue identity politics, by attaching ourselves not to sexual or gender identities, but by standing in solidarity with those living on the margins; by constructing alternatives

13 The terms "homoantagonism" and "transantagonism" were introduced by writer Robert Jones, Jr. (known as the Son of Baldwin), used respectively instead of "homophobia" and "transphobia," aptly regarded as an ableist obfuscation of this type of violence.

14 "Lebanon: Syrian Refugee's Account of Torture." Human Rights Watch, 21 Dec. 2016, available at: https://www.hrw.org/news/2016/12/21/lebanon-syrian-refugees-account-torture

15 Wansa, Sarah. "Torture at Every Stage: The Unofficial Narrative of the Hammam al-Agha Raid." Legal Agenda, 12 Nov. 2014, available at: http://legal-agenda.com/en/article.php?id=3043

16 Frangieh, Ghida. "The Hammam al-Agha Raid: Collective Prosecution in Violation of Individual Rights." Legal Agenda, 18 Sept. 2014, available at: http://legal-agenda.com/en/article.php?id=650\&folder=articles\&lang=en

17 "'It's Part of the Job:' III-Treatment and Torture of Vulnerable Groups in Lebanese Police Stations." Human Rights Watch, June 2013, available at: https://www.hrw.org/sites/defaultfiles/reports/lebanon0613 forUpload 1.pdf 
instead of seeking the recognition and approval of oppressive structures; by carving and holding spaces with transformative potential; by subverting power rather than seeking integration into institutions of power. We can only do that by positioning ourselves not as an isolated oppressed population divorced from our context, but as part of a struggle that can only exist at the intersection of other struggles - with the dream of liberation for all. ${ }^{18}$

18 This piece was written with a love for the magical potential of dreaming in public; it is an invitation to collectively envision spaces for liberation. 